\title{
Assessing the Extent and Nature of Chronic Poverty in Low Income Countries: Issues and Evidence
}

\author{
ANDREW MCKAY and DAVID LAWSON \\ University of Nottingham, UK
}

\begin{abstract}
Summary. - Discussions of chronic poverty have mostly considered its monetary dimensions, with current evidence suggesting that such poverty is much more transient than chronic. But chronic poverty is a real and important phenomenon, potentially more important quantitatively than it first appears once account is taken of different methodological approaches and inevitable measurement difficulties. The chronic poor have distinctive characteristics, such as lack of assets or high dependency rates, which may account for their persistent poverty. The paper argues that it is also necessary to develop concepts of chronic poverty further, covering relevant nonmonetary dimensions and not just relying on panel data.

(C) 2003 Elsevier Science Ltd. All rights reserved.
\end{abstract}

Key words - chronic poverty, low-income countries, panel data

\section{INTRODUCTION}

Measures of living conditions at a point in time do not necessarily provide a good indicator of their likely stability over time. For many purposes it is important to adopt a dynamic perspective, distinguishing between transient and chronic (persistent) deprivation. This distinction between chronic and transient poverty is important for policy purposes, given that different policy responses are likely to be appropriate for each. For instance, this distinction is relevant for questions of targeting and social protection.

In empirical work, the importance of distinguishing chronic and transient poverty has been recognized particularly in relation to income or consumption poverty. But the same point applies to some other dimensions of living conditions, though not to all. A child may currently be attending school, but that does not guarantee that she will not drop out before completing her studies, or even still be at school next year. By contrast though, the fact that an adult is literate now is generally a reliable indication of future literacy status.

In the context of this special issue, this article reviews currently available evidence on the extent and nature of chronic poverty with reference to low-income countries. It builds on a recent review of poverty dynamics in developing countries (Baulch \& Hoddinott, 2000), which itself supplies some estimates of chronic income or consumption poverty. Their article suggested, in line with a number of other studies, that quite a large proportion of poverty is in fact transient, although it also recognized that fluctuations in income or consumption levels often led to persistent poverty.

This paper builds on this earlier survey in several respects. First, it focuses explicitly on the characteristics of the chronic poor, contrasting them with the transient poor, and argues that they are an important distinct group. Second, based on a review of the underlying methodological issues in its measurement, it argues that many existing studies may underestimate the quantitative significance of chronic poverty. It also argues for the need to develop broader concepts of chronic deprivation covering other dimensions and sources of information (not just relying on panel data), and considers proxies for chronic poverty that are sometimes proposed.

The paper is structured as follows. Section 2 addresses the issue of defining chronic poverty, setting out the various difficulties that arise in practice and discussing data sources. The analysis of chronic poverty is generally based on longitudinal or panel datasets and income or consumption poverty; Section 3 reviews evidence from a number of low-income countries on the extent and nature of chronic and transient poverty based on such datasets, as well as 
the factors associated with transitions. Section 4 discusses the options for measuring and characterizing chronic poverty in situations where standard longitudinal datasets are not available. Section 5 concludes and identifies priorities for future research.

\section{CONCEPTS AND MEASURES OF CHRONIC POVERTY}

The defining feature of chronic poverty is its extended duration (Hulme, Moore, \& Shepherd, 2001; Hulme \& Shepherd, 2003). Thus while many move into and out of poverty over time (the transient poor), the chronic poor suffer persistent deprivation. This chronic poverty may also be severe (in terms of depth) or the deprivation may be multidimensional in nature, but these are more potential characteristics (the importance of which needs to be demonstrated by empirical evidence) than defining features of chronic poverty.

The distinction between chronic and transient poverty has typically been based on longitudinal or panel data, where observations of the living conditions of the same individuals or households are made at several points in time. Much of this analysis has focused on monetary measures of living standards, partly because these are among the measures that can fluctuate most over even quite short time periods (within and between years). Their measurement at a single point in time clearly fails to capture this dynamics. But as argued above, the chronictransient distinction is also relevant for other dimensions of deprivation, for instance malnutrition (aspects of which such as weight-forheight can also fluctuate significantly in the short term). Furthermore, the necessary data are often available (e.g., from panel surveys conducted over a short period, such as the first and second rounds of the Ghana Living Standards Survey), even if they have not been widely used for this purpose.

An alternative approach for studying chronic deprivation is based on information that captures dynamic aspects of living conditions even by just observing at one point in time-such as retrospective questions or life histories, or one-time indicators that have implications for duration, such as illiteracy or stunting. This approach is complementary to studying chronic poverty based on panel data and monetary measures of living conditions. In addition, this approach offers advantages such as the ability to look over longer time horizons, and the fact that it will not be affected by short-term fluctuations. This approach though has been much less commonly applied in looking at quantitative aspects of chronic poverty, so there is scope for considering it much more.

This section discusses issues relating to the measurement of chronic and transient poverty based on panel data; options in the absence of panel data are discussed in Section 4, along with a discussion of the types of conclusions that can be drawn in such instances.

\section{(a) Panel datasets and their limitations}

In instances where a given survey is repeated in a later year, this provides valuable information about net changes in poverty in aggregate or for a particular group or cohort (which may be defined according to different criteria). ${ }^{1}$ But only when these surveys comprise a panel component can they provide any information on the extent of movements of households and individuals into and out of poverty between the different rounds. In Uganda for instance the poverty headcount fell from $55.7 \%$ of the population in $1992-92$ to $34.2 \%$ in $1999-2000$ (Appleton, 2001, Table 1), a decline of $20.4 \%$ points. But, an examination of those households that were in the panel between these two rounds, among whom the decline was $17.5 \%$, shows that between these years $29.2 \%$ of households moved out of poverty and $11.7 \%$ moved in -in other words there was substantial mobility (Deininger \& Okidi, 2002).

Compared to the overall number of household surveys that have been conducted over the past 15 years or so, only a relatively small number of panel datasets suitable for poverty analysis have been collected. This reflects the practical difficulties involved in their collection as well as insufficient demand to date for such data. Where panel data have been collected, the number of waves, the sample size, their geographic coverage and the periods covered all vary from case to case (see McKay \& Lawson, 2002 for examples). The panels are almost always of households (rather than of individuals), and in most cases involve repeat visits a few years apart (often three to five) and relatively few rounds. Some instances however, involve frequent repeat visits, even sometimes in adjacent years (e.g., the ICRISAT panel dataset in rural South India); some involve long time horizons (up to a generation) while others involve repeat visits within the same year (so 
providing information about seasonal chronic poverty).

It is important though to recognize that panel data also suffer from various limitations that need to be considered carefully. The impact of measurement error in looking at individual or household-level variations between two rounds can be considerable (Glewwe \& Jacoby, 2000). In addition, because the individual or household has been surveyed in the same context before, the dynamics of a second interview may differ significantly from the first; thus data quality may improve or deteriorate between the two interviews, an issue which is particularly serious when looking at changes. An extreme instance of this may be where the household refuses to co-operate the second time around, meaning that longitudinal information is not available for that household.

This last point is a specific instance of the more general problem of attrition, which can also arise for other reasons, notably because a household may have moved away and so cannot be found or followed up, or may no longer exist (following death, household breakup etc.). In such cases a panel observation is lost (in particular it is not correct to replace the household by the one now occupying the same dwelling). This attrition matters for analytic purposes because the households that remain in the panel are liable to be systematically different from those that dropped out. Thus some of those that dropped out may have been more economically dynamic, which may have led them to move to pursue new opportunities. Others may have been much poorer which itself might have been a contributory factor leading to household breakup or to greater risk of mortality. While econometric techniques have been developed for trying to allow for this potential "attrition bias" they are necessarily imperfect and approximate. A less extreme case is where households have changed their composition or other characteristics significantly between the two rounds. This raises the issue of at what point this can no longer be considered to be the same household. ${ }^{2}$

\section{(b) Concepts and measures of chronic poverty based on panel data}

Two main methods have been adopted to identify and measure chronic poverty (in practice chiefly income or consumption poverty) based on suitable panel data: the "spells" and "components" approaches (Yaqub, 2000). In the spells approach, the chronic poor are identified based on the number or length of spells of poverty they experience-so that all poor households are classified as either chronic poor or transient poor. For instance, Baulch and McCulloch (1998), using a five-round panel dataset for rural Pakistan, find that only $3 \%$ of the households were income poor in all five years. Fifty-eight percent though were poor in at least one period, suggesting a very high degree of movement into and out of income poverty. Using the ICRISAT panel dataset from rural South India, Gaiha and Deolaiker (1993) find that $21.8 \%$ of households were income poor in each of nine consecutive years (87.6\% of all households surveyed were poor in at least one of the nine years).

The "components" approach distinguishes the permanent component of a household's income or consumption from its transitory variations, and identifies the chronic poor as those whose permanent component is below the poverty line. A common approach to identifying the permanent component is based on the intertemporal average for the household (Jalan \& Ravallion, 1998; McCulloch \& Baulch, 1999). An alternative procedure for identifying the permanent component is based on the predictions of a statistical (regression) model capturing the relationship between a household's income or consumption level and its characteristics; such models aim to purge the effect of transitory shocks. Thus Gaiha and Deolaiker (1993) base their concept of "innate poverty" on the predictions of a panel data regression of income on household characteristics, estimated using the fixed-effects method. Their innate poverty can be interpreted as a concept of chronic poverty following the components approach, where this identification of the chronic poor takes account of the households' characteristics.

The logic underlying the components approach is that it may be feasible using good quality panel data, even covering relatively short time periods, to identify those that are unlikely to escape poverty permanently over a significant period of time given their characteristics. The relevant characteristics will be those used in predicting the low permanent income levels. The accuracy of using this to predict poverty status into the future will depend on the extent to which these characteristics change in the future, something which is obviously unknown but may be predictable to 
some extent (for instance, if the children of a poor household are currently attending school).

In both approaches a number of issues arise. In the case of the spells approach, a number of different criteria may be applied, relating to the number or length of periods of poverty experienced. One intuitive, but demanding, criterion for chronic poverty is that the household's income or consumption level must fall below the poverty line in each period in which they are observed. According to this, a household with an income above the poverty line in just one period in which they were observed would not be classified as chronically poor, even though they may be poor in several other periods in which they are observed.

A different approach is to focus on the length of time for which someone is poor. For instance, a household may be considered to be in chronic poverty if it is identified as poor in three consecutive periods. A difficulty arises here however, because of the truncated nature of the available information; income levels before or after the survey period are not observed, and so it is not known whether the individuals were poor immediately preceding or following the time when they were observed. In addition, it is rarely the case that individuals or households are observed for several consecutive years; often there may be three to five years between each observation. Therefore, even if it is known that someone is poor at two or more points in time separated by several years, this does not indicate whether they were poor in the years in between.

In the case of the components approach, it does not necessarily correspond to the concept of persistent poverty. A household may fluctuate in and out of poverty, but where the permanent component of its living standard is below the poverty line it is considered chronically poor. This implies that whether this household is considered as chronically poor will also reflect the depth of poverty it experiences. A second main issue concerns the procedure by which the permanent and transitory components of income or consumption are distinguished. Of the two approaches outlined above, that using the predictions of the regression model taking account of household characteristics is preferable in principle. But, its reliability in identifying permanent and transient components will depend on how well the household characteristics are able to explain the variations in income or consumption.
One general point to note in both approaches is that the results may be sensitive to the level at which the poverty line is set (Muller, 2000) or to the precise definition of the standard of living measure. ${ }^{3}$ Most of these difficulties are inevitable, but they obviously have implications for the ease with which the results of different studies can be compared.

For both methods, one major issue is measurement error, to which this article now turns.

\section{(c) The importance of measurement issues}

Measurement issues can play a large part in the quality of data and therefore the levels of confidence that can be placed on findings. Measurements of individual household income or consumption are inevitably subject to error, due to factors such as straightforward recall error, the need to impute missing data values and the inaccuracies in grossing up data collected based on short-period recall to obtain monthly or annual estimates (including the effects of seasonality). This is true in all quantitative work on poverty, but applies particularly to looking at poverty dynamics based on panel data. Measurement errors will inevitably suggest more individual/household variability in consumption or income than there actually is (and hence more movements into and out of poverty according to the spells approach). ${ }^{4}$ Measurement error will also affect the accuracy of the identification of permanent and transitory income or consumption on which the components method relies.

Two main methods commonly adopted in assessing the effects of measurement error are to compare patterns of chronic poverty for different standard of living measures, and to attempt to adjust for the effects of measurement error. As regards the former, one common approach is to compare patterns of chronic poverty obtained using consumption and income based standard of living measures, given that many surveys enable both to be computed. Consumption tends to be the preferred measure, both for theoretical reasons (the practice of consumption smoothing means that income may not be as good a measure of living conditions as consumption) and because it is generally considered to be more accurately measured. It follows that consumption generally exhibits lower variance levels than income. Given this, it would be reasonable to assume 
that the extent of chronic and transient poverty may vary to some extent just by changing the welfare measure. This point notwithstanding, it is wise to test the robustness of the observed pattern of chronic poverty by undertaking sensitivity analysis on the choice of measure. Thus, for example, based on a three-wave panel for rural India covering 1969-71, Gaiha (1988) found that $86 \%$ of the income defined chronically poor were also chronically poor under the expenditure measure, in other words quite a high degree of convergence.

The second approach is to attempt to adjust for the effects of measurement error as, for example, have McCulloch and Baulch (2000). In this case, income was the only monetarybased measure available for all five years of the panel dataset. To allow for the effects of measurement error on the results, they constructed a simple model for the three years that they had both income and consumption expenditure observations and estimated the measurement error. ${ }^{5}$ From this, they calculated and then used an adjusted income variable as the basis for computing the extent of chronic monetary poverty. ${ }^{6}$ Similarly Scott (2001), working on poverty transitions work in Chile, crosschecked transitory income against harvest changes, livestock output, household wealth change. The effect of measurement error can be quite substantial; in Ethiopia, Dercon and Krishnan (2000) found that measurement error might account for up to a half of the household mobility across consumption quintiles.

\section{(d) Nonmonetary dimensions of chronic and transient deprivation}

While the distinction between chronic and transient deprivation has been discussed so far principally with reference to income or consumption of living standards (reflecting common practice in the literature), the distinction is relevant to other dimensions as well, though not necessarily all (see Baulch \& Masset in this issue for an example based on panel data from Vietnam). One important instance is short-term aspects of nutritional status. For instance, the weight-for-height anthropometric measure can fluctuate quite significantly over relatively short time horizons, for various reasons such as the period of the agricultural season or the effects of disease. Again it is important to separate out cases of transient weight-for-height malnutrition from chronic instances. But this chronic/ transient distinction is not relevant in all instances. For example, if height for age malnutrition is regarded as reflecting past events and being less easily reversed-a perspective that is not universally accepted - then the transient/ chronic distinction is less relevant in this instance. Similarly, in the case of education, whether or nor a child is enrolled in school can fluctuate over time, as children may drop out temporarily or withdraw permanently; the same is clearly not true of literacy status.

The chronic-transient distinction is also potentially relevant for other dimensions of deprivation such as ill-health, vulnerability or empowerment, but in each case this has not been considered in depth. In some cases (such as ill-health, where this distinction is clearly important) available information often does not enable this distinction to be made in practice. For some other dimensions (e.g., vulnerability) this may be due to difficulty in quantifying the underlying concept, let alone distinguishing any chronic or transient components.

The vast majority of the analysis to date has been based on monetary measures of living conditions, though relating these to household characteristics (covering many different dimensions). There is opportunity and scope to investigate similar concepts of chronic and transient deprivation in other dimensions of well-being and this is an important direction for future research.

In summary, panel datasets represent a rich source of information for assessing the extent and nature of chronic and transient poverty. Inevitably different studies and researchers use different approaches for defining both poverty in general and chronic poverty in particular, which does introduce questions of comparability across studies. In all instances it is important to emphasize that the concept of chronic poverty can be meaningfully applied over different horizons, ranging from intrayear variations (where chronic poverty is that poverty which persists over the whole agricultural season) to intragenerational (where chronic poverty implies that poverty which persists from one generation to the next). The nature of chronic poverty in these two extreme cases is somewhat different, with the nature of chronic poverty becoming much more severe as longer time horizons are considered. ${ }^{8}$ But the principles for distinguishing chronic and transient poverty are broadly similar, even if their interpretation is different. 


\section{PANEL DATA EVIDENCE ON THE EXTENT AND NATURE OF CHRONIC POVERTY IN LOW-INCOME COUNTRIES}

As different studies have adopted varying concepts in analyzing chronic poverty, this can raise serious problems in making cross-study comparisons, and more generally in forming conclusions about global patterns of chronic poverty. But provided this is kept in mind, it remains informative to discuss the findings associated with chronic and transient poverty, including the characteristics associated with each. Indeed the characteristics can generally be more easily compared than the levels.

This section focuses on information from longitudinal (panel) datasets and on income or consumption poverty, which as noted above is currently the source of most information on chronic poverty.

\section{(a) Evidence on the extent of chronic poverty}

Estimations of the extent of chronic poverty will depend on whether the spells or components approach is adopted. For instance, in rural South India Gaiha and Deolaiker (1993) find that only one-third of those defined as innately poor, that is as having permanent income levels below the poverty line, are poor in each of the nine rounds of data available. Within each of these approaches, estimates will also depend on the precise manner in which they are implemented (see previous section).

Considering a spells approach to chronic poverty, Baulch and Hoddinott (2000) summarize a number of important studies by classifying households as "always poor," "sometimes poor" or "never poor." Setting aside those households that are never poor, in all cases only a minority of the rest are classified as always poor. In some cases this is only a small minority though, of course, this may partly reflect the number of rounds in the panel (other things being equal, a household is less likely to be always poor the greater the number of time periods observed). But the relative importance of the always poor group (one criterion for chronic poverty), compared to the sometimes poor group, also varies according to the study population. For example, around a quarter of the households that experienced poverty at some point in the nine years of the ICRISAT panel are classified as always poor (Gaiha \& Deolaiker, 1993), whereas the corresponding figure for the five year Pakistan panel is around one-twentieth (McCulloch \& Baulch, 1999). In addition, another factor affecting the estimated magnitude of chronic poverty is whether income or consumption measures are used to measure living standards, with estimates of the always poor group generally being lower when income based measures are used because of their generally greater variance compared to consumption measures (Baulch \& Hoddinott, 2000, p. 11).

Care should be adopted however, when interpreting some of these categories, as households in the sometimes poor group are likely to exhibit heterogeneity. For example, households who are poor in just one period are included in the sometimes poor grouping along with households who are poor in all but one of the periods. The results could therefore change significantly with slight variations in definition (or when disaggregating the sometimes poor group further).

The same survey article also considers the proportion of households within these panel datasets that move from one quintile group to another over relatively longer periods of time. Of particular relevance here is the percentage of households originally in the lowest (poorest) quintile that remain there (which might be considered as a concept of chronic relative poverty) ${ }^{10}$ compared to those who move over time into higher quintile groups. In several cases quite high proportions of households remain in the lowest quintile. In the studies of India, Peru, South Africa and Vietnam, more than $40 \%$ of the households in the lowest quintile remained there over periods of time ranging from five to nine years.

The results of various individual studies of chronic poverty, as well as the summary presented by Baulch and Hoddinott (2000), might be interpreted as suggesting that transient income is quantitatively much more important than chronic poverty. But that would be an inappropriate conclusion for many reasons. It focuses only on the numbers in poverty, and not on the depth or severity of that povertywhich might be greater for the chronic poor. In addition, the always poor concept used by Baulch and Hoddinott (2000) is a relatively stringent criterion for chronic poverty, especially in instances where households are observed over several periods. More importantly, this conclusion about the extent of chronic poverty does not take due consideration of measurement error, which is a very real issue in looking at changes for individual households 
and which, if not allowed for, will inflate the degree of mobility, and so the extent of transient poverty, in the data. Several studies do not take measurement error into account, and even those that do may not be able to correct for it fully. Thus, in summary, there is good reason to think that chronic poverty is in fact quantitatively more important than Baulch and Hoddinott's summary tables might at first sight suggest.

\section{(b) Characteristics of the chronic poor}

By focusing on the characteristics of individuals and households in chronic poverty, this allows consideration not just of how chronic poverty differs from transient poverty, but perhaps more importantly allows policy trying to combat chronic poverty to be based on a solid understanding of its likely underlying determinants. The characteristics most commonly associated with chronic poverty include being in a disadvantageous situation with respect to one or more of the following: human capital; demographic composition; location; physical assets; and occupational category, among others. This corresponds closely to prior expectations, and also to the asset-based understanding of chronic poverty developed by Gaiha (1992), where chronic poverty reflects low levels of asset holdings and/or persistently low returns on assets.

\section{(i) Human capital}

Intuition suggests that increasing human capital will decrease the probability of being chronically poor, and available evidence relating to education generally supports this. Various researchers find that increased levels/years of education decrease the probability of being chronically poor (Adam \& Jane, 1995, in Pakistan; Campa \& Webb, 1999, in Peru). In some instances it is the higher levels of education, such as secondary schooling, that matter for escaping chronic poverty (McCulloch \& Baulch, 2000; Jalan \& Ravallion, 1999, 2000; for Pakistan and China respectively).

Several studies also find that illiteracy is positively related to chronic poverty (e.g., Jalan \& Ravallion, 1999, 2000 for rural China; Mehta \& Shah, 2001 for India). But it is not always just human capital obtained from formal education that matters; Gaiha and Deolaiker (1993) suggest for rural South India that innate disadvantages, such as the lack of management skills, are positively and significantly associated with chronic poverty.

\section{(ii) Demographic factors}

Other things being equal, increased household size is likely to place extra burden on a household's asset/resource base and would generally be expected to be positively related to chronic poverty. Many studies provide evidence for this (McCulloch \& Baulch, 2000, for Pakistan; Jalan \& Ravallion, 1998, 1999, 2000, for rural China; and Aliber, 2001, for South Africa). Increased dependency ratios, the number of children, and the presence of a third generation in a household are other demographic factors associated with chronic poverty (Jalan \& Ravallion, 1999, 2000; McCulloch \& Baulch, 2000). But, while these aggregate correlations highlight an important finding, at the same time they may hide a greater complexity in some specific cases. For instance, for those reliant on peasant agriculture for their livelihood, a large household size may actually be beneficial in enabling them to overcome labor shortages at critical periods.

Single parent headed households are more likely to be amongst the long-term poor (e.g., South Africa). In India (Palanpur), Lanjouw and Stern (1991) found chronic poverty to be disproportionately high among marginalized groups such scheduled tribes, the elderly women and the disabled.

\section{(iii) Location}

In general, chronic poverty like overall poverty is much more prevalent in rural areas compared to urban areas (e.g., Deininger \& Okidi, 2002, for Uganda), and this is particularly so in remote rural areas (this being another of Lanjouw and Stern's marginalized groups in Palanpur). Findings in this issue support this finding (Bird and Shepherd, Mehta and Shah) and point out that mountainous areas may be particularly likely to have concentrations of chronic poverty (Baulch for Vietnam and McCulloch for Sichuan, China). Location in fact plays a major part in the opportunities available to households and therefore the probability of being classified as long-term poor.

\section{(iv) Physical assets}

Lack of physical assets is another important factor often associated with chronic poverty (Adam \& Jane, 1995; McCulloch \& Baulch, 2000, both for Pakistan). Among these assets 
land ownership is particularly important (Gaiha \& Deolaiker, 1993; Jalan \& Ravallion, 1999, 2000; Mehta \& Shah, 2001). This is consistent with the earlier observation by Lipton (1988) that landlessness or near landlessness, at least on good or well-watered lands, is highly correlated with high-poverty incidence and severity (or ultra-poverty). He also argues that other factors are important including tenancy, remote land and land that has been fragmented into smaller sizes.

A number of authors though have argued that asset accumulation is far less important than the returns to endowments (Glewwe \& Hall, 1998; Lanjouw \& Stern, 1993). Gaiha (1992) argued for India that the low variation in endowments/returns from assets (such as arable land) might be as important, as asset quantity, in predicting chronic poverty. Gunning, Hoddinott, Kinsey, and Owens (2000) found that asset accumulation via steady investment in land quality, together with considerable learning by doing, was far more effective in raising income.

\section{(v) Occupational status}

Economic activity status is another important correlate of chronic poverty, though the nature of the correlation can differ from one country to another. Okidi and Kempaka (2002) found for Uganda that self-employed farming households are more likely to be chronically poor. This should not come as a big surprise, in view of both the predominance of agriculture as a source of employment for Uganda's poor, and the relatively limited market integration of most of the rural producers. ${ }^{11}$ Related to this, low food grain yields were found to be positively associated with chronic poverty in China (Jalan \& Ravallion, 1999, 2000), a result which would be expected in other economies where large proportions of the population are engaged in peasant agriculture. This of course raises the issue of what underlies the low food yields; it may, for instance, reflect factors identified above such as lack of physical assets of a disadvantageous location.

In contrast to this, Campa and Webb (1999) found for Peru that chronic poverty was positively associated with household heads that were employed outside of the household. This suggests that in this case there is little difficulty in obtaining employment, but problems in finding sufficiently remunerative employment. In other instances, notably industrialized and transition countries, there is a natural linkage between loss of employment, loss of income, and increased probability of long-term poverty. This highlights the unsurprising fact that which occupational categories are disproportionately associated with chronic poverty will vary from one country to another, and are also likely to differ within countries.

While various other factors have been identified as important correlates of chronic poverty, these tend to be specific to a limited number of cases and so are not reviewed here.

\section{(c) Characteristics of transient poverty}

Given the emphasis that has been placed on chronic poverty, it is important to consider to what degree the characteristics of the chronic poor differ from the rest of the poor (i.e., the transient poor), to judge to what extent this distinction is helpful for policy and for understanding causes of poverty. Given the more temporary nature of transient poverty, it is reasonable to expect that the factors associated with transient poverty may differ from those for chronic poverty.

Some factors do though appear to be important for both transient and chronic poverty, notably human capital. Evidence from some studies suggests that increased education in general (McCulloch \& Baulch, 2000), or specifically of the household head (Jalan \& Ravallion, 1998), reduces transient poverty. This suggests that more educated households are better able to protect themselves against fluctuations in their long-term conditions. Human capital not only raises a household's asset levels, thus helping it move out of chronic poverty, but also enables the household to cope better with transitory variations. Some studies find demographic factors to be important for transient poverty as well, though generally less so than for chronic poverty. For instance, in rural China, Jalan and Ravallion (1998) found transient poverty to be higher among small households. In this case, poverty among small households could reflect seasonal labor shortages (which could limit their ability to smooth their consumption levels). By contrast, $\mathrm{McCul}-$ loch and Baulch (2000) find for Pakistan that larger household size is associated with increased transient poverty.

In rural China transient poverty tends to be higher for those households with lower farm yields and less wealth (Jalan \& Ravallion, 1998). It is also higher for those households using modern agricultural techniques and those 
experiencing large wealth fluctuations. The former would imply that modern techniques lead to higher average yields but incorporate higher risk, and supports the conclusion that high uninsured income risk underlay the transient poverty. In India, Gaiha and Deolaiker (1993) found factors such as adverse price movements to be more closely associated with transient poverty than with chronic poverty. Again, it is the inability of many households to insure themselves adequately against fluctuations in their living conditions which leads them temporarily into poverty.

In South Africa, Carter and May (1999) found that households in receipt of nongovernment transfers, such as remittances from families, are by and large transitorily poor. This emanates from the relative irregularity of such transfers, compared to government transfers which are regular and usually more reliable.

In looking at intrayear chronic and transient poverty in rural Rwanda in the 1980s, Muller (2000) often found the correlates to differ, but a substantial share of poverty was seasonally orientated. ${ }^{12}$ The adoption of low-risk strategies by many farm households (e.g., cultivating staple crops such as sweet potatoes with low commercial returns) was positively correlated with chronic seasonal poverty. In contrast the cultivation of cassava, which can be kept in the ground for most of the year and used in famine periods, had a negative effect on transient poverty. Specific cultivation patterns and practices then may be important factors underlying chronic poverty, not just within, but also between years.

Many of the factors identified as important characteristics of transient poverty have also been identified as having an association with poverty transitions. For instance, several studies emphasize the importance of assets, both physical and human, in influencing poverty transitions. ${ }^{13}$ Thus higher levels of education and ownership of livestock increase the likelihood of exits from poverty and reduce the likelihood of entry to poverty in rural Pakistan (Baulch \& McCulloch, 1998). Also in Pakistan, Adam and Jane (1995) report that changes in assets (land ownership, education, migration) were responsible for one-quarter of income changes in the poorest quintile group, but that these factors contributed relatively less to income changes in less poor groups. Higher levels of human capital in urban areas and physical capital in rural areas in Côte d'Ivoire increased the likelihood to escapes from poverty in the 1980s in a situation of general economic decline (Grootaert \& Kanbur, 1995; Grootaert, Kanbur, \& Oh, 1997). Several factors that are good correlates of poverty status, such as dependency ratios, are poor correlates of poverty transitions. This is entirely consistent with the fact that such factors tend to be more strongly associated with chronic rather than transient poverty.

In summary, while some factors associated with chronic poverty (such as low educational levels) are also associated with transient poverty, many differ. Empirical evidence strongly supports the view that transient poverty is associated with an inability of households to maintain their consumption levels in the face of fluctuations or shocks affecting their incomes or individual circumstances. The relatively different characteristics associated with chronic and transient poverty lead Jalan and Ravallion $(1999,2000)$ and Gaiha and Deolaiker (1993) to suggest that different policy responses are likely to be appropriate in each case.

\section{QUANTITATIVE ASSESSMENT OF CHRONIC POVERTY WITHOUT PANEL DATA}

Extensive resources are required to form panel datasets, and they are therefore relatively rare. Thus, as emphasized in Section 2, panel datasets are not available in many instances, even though one-off or repeated cross-sectional household survey datasets often will be. This means that it is not possible to trace the fluctuations of income, consumption or other variables over time for individual households or their members, simply because the individual or household is only observed once. In such circumstances, is it possible to say anything about poverty dynamics in general, and chronic poverty in particular?

One way of doing so is to seek to identify the chronic poor by looking at characteristics that, though only observed once, provide information about past living conditions. Alternatively, with certain assumptions and or limitations, it is possible to assess aspects of dynamics based on repeated or even one-off household surveys. As stressed above these approaches offer certain advantages relative to panel data-in particular the effects of measurement error are less severe. This section briefly summarizes these different approaches, assessing their strengths and weaknesses and providing 
examples of the types of information they can provide.

\section{(a) Using repeated cross-sectional surveys in assessing dynamics}

Instances where repeated cross-sections are available can be used to consider changes in poverty in aggregate and for appropriately defined cohorts or subgroups of the population (for example, according to geographic location or main activity). This identifies the direction and magnitude of the overall change in poverty experienced by the different cohorts. By focusing on overall measures of poverty for a group, it offers the advantage that, because of the averaging this involves, the changes are more accurately measured than those for individual households within a panel. These groups can be defined at different levels of detail, though attention needs to be paid to maintaining an adequate sample size.

Of course, these comparisons say anything about dynamics within these groups, in other words, about the extent of movements into and out of poverty within the groups (which as noted in Section 2 can be considerable). While not distinguishing chronic and transient poverty at the individual or household level, this can still provide valuable information on chronic poverty for groups of households. For instance, in a study of poverty in Ghana over the 1990s based on two cross-sectional surveys, Coulombe and McKay (2002) found that while poverty was decreasing at the national level, poverty among those resident in rural areas in the northern savannah zone hardly changed. Thus this last group as a whole clearly experienced persistent poverty, strongly suggesting that many households there were also chronically poor.

\section{(b) Proxies for chronic poverty: depth and multidimensionality}

Another approach to identifying chronic poverty without panel data is to focus on what might be considered as proxies for persistent poverty - to identify those suffering deep or severe poverty, or those experiencing multidimensional deprivation (Hulme et al., 2001). If these can be assumed to indicate persistence of poverty, they can be identified based on observations made at a single point in time, through a survey or otherwise. Depth and severity of poverty are concepts most commonly associated with income or consumption poverty, though have also been applied to malnutrition; they focus on the extent to which income, for instance, falls short of the poverty line. Poverty depth or severity is not the same as chronic poverty; however, the aforementioned approach assumes that there is a substantial overlap between these two groups.

Multidimensionality of deprivation can be identified from any information source that provides information on a range of key dimensions of living standards (for instance, education, health, lack of access to facilities, poor quality housing conditions, among others). But the main issue in this case is to define what multidimensional deprivation means: which dimensions, and, in each case, what constitutes deprivation? What about those that are deprived in some dimensions, but not others? Should different dimensions be combined, and if so how? To date there has been little attempt to do this at the household level, though it has been widely attempted at the national and regional levels, for example, the UNDP's family of indices measuring human development.

In seeking to identify those suffering deep or severe poverty, this generally relates to a state where an individual or household's standard of living measure is a certain percentage below the "normal" poverty line. Many poverty studies do this, for example, identifying the extreme poor (or ultra-poor) in addition to those classified as poor. In a recent study in Rwanda, the severely poor were defined as those whose total consumption standard of living measure fell short of even the food poverty line (Republic of Rwanda, 2002). Severe poverty thus defined was associated with factors that may credibly be considered as characteristics of the chronic poor, such as rural location, working as an agricultural labor or an own account farmer, small land size, and households headed by female widows. In Nigeria Canagarajah and Thomas (2001) found groups such as the following to be disproportionately represented among the extremely poor households: those whose head possessed little or no schooling, those whose head was self-employed and those spending $80 \%$ of their income on food. These are characteristics that are quite likely to be associated with chronic poverty.

The critical question in all this is how reliable a proxy severe poverty is for chronic poverty. This can be assessed in situations where both chronic and severe poverty can be defined, in other words cases where a panel is available. In 
the case of Kwa-Zulu Natal, South Africa this proxy is found not to be accurate (Aliber, 2001). This may though raise the issue of how accurately the chronically poor have been identified by the panel dataset, given the problem of measurement error.

A different concept of severe poverty discussed by Mehta and Shah (2001) for India focused on the inability to consume two square meals a day. An element of caution should be adopted with such measures of hunger, as this direct question may result in biased responses/underestimation. Nonetheless it may offer another concept of severe poverty that can also be used to provide a geographic profile.

To date there has been very little empirical study of multidimensionality as a proxy for chronic poverty, no doubt in part because the conceptual basis for this is not well developed.

(c) Other methods of using household surveys to assess chronic and transient poverty

Two other methods have been developed which their authors argue can distinguish chronic and transient poverty without having panel data available. Suryahadi and Sumarto (2001) distinguish the chronic and transient poor based on single cross-section surveys in Indonesia using an approach superficially similar but different in detail to the components approach. They estimate a regression model of the relationship between a household's consumption level and its characteristics. However, as some types of households may experience bigger fluctuations in their consumption levels than others, they allow the residual error term of the regression (which considers transitory fluctuations among other things) also to vary with (a potentially different set of) household characteristics. This model is used as the basis for assessing vulnerability of households to consumption poverty. But they also use the predicted values of this model (an estimate of the permanent component) to distinguish between the transient poor (those whose current consumption falls below the poverty line, but their predicted consumption lies above it) and the chronic poor (those whose actual and predicted consumption levels both lie below the poverty line). Using this method over the period 1996-99, Suryahadi and Sumarto (2001) argue that most of the increase in poverty in Indonesia since the economic crisis of 1997 was due to increased chronic poverty. They also find that the number of households classified as having a "high" vulnerability to poverty increased dramatically from $6.8 \%$ of households to $18.4 \% .{ }^{14}$ This suggests that a much higher proportion of households are "likely" to fall into chronic poverty, in the future. This suggests how shocks may be important in giving rise to chronic, in addition to, transient poverty.

This method is different from the components approach for panel data outlined above because it uses only information on variations between households at a point in time, and no information on variations for each household over time. Both are used in applying the components approach using panel data, and given that the time dimension is fundamental, this raises serious questions about how accurately Suryahadi and Sumarto's method can identify the chronic poor. In addition, the point made for the components approach above, that the reliability of the identification of the chronic and transient poor will depend on the accuracy of the identification of the underlying relationship between consumption and household characteristics, applies even more forcefully in this case.

A different approach has been developed by Gibson (2001), which he argues can be used to identify chronic consumption poverty in the absence of a panel. This method is based on the fact that consumption data - are especially for frequently purchased items such as food-are frequently collected on a short-period recall basis, to facilitate more accurate response. As observed by the late Chris Scott (1992), because the recall period is short it will not be typical. Thus this reliance on short-period recall is likely to exaggerate extremes, and so also to exaggerate levels of poverty. Assuming for purposes of illustration that the recall period is one week, Scott showed that this exaggeration could be allowed for given knowledge of the extent of correlation between the consumption levels in the recall week and in the subsequent week(s). If this information is available, it is possible to construct more accurate estimates of monthly or annual consumption than by just multiplying the short-period recall with the appropriate factor $(30 / 7$ or 52 respectively in this example).

To compute the necessary correlation coefficient requires that at least a subset of the households in the survey have been enumerated throughout the year, collecting information on their consumption levels each time. Given this it is possible to estimate annual consumption 
for the remaining households that were surveyed only once. Gibson applies this based on household survey data for Papua New Guinea. $\mathrm{He}$ then compares poverty estimated in this way with poverty estimated by simply grossing up for all households, ignoring the correlation issue. He identifies as the transient poor those identified as poor in the latter case but not in the former, and the chronic poor as those poor in both cases.

This does not however, correspond to a distinction between transient and chronic poverty. It is rather an important demonstration of the consequences of this specific mismeasurement of poverty. What Gibson classifies as the transient poor are those households that are incorrectly identified as being poor using the commonly applied technique (where the correlation information is not available). Similarly, the chronic poor are those correctly identified as poor using the commonly applied technique. In other words this does not even correspond to intrayear transient and chronic poverty (which could only be distinguished for the subset in the panel). His method and demonstration is important, but not as a way of distinguishing chronic and transient poverty. This method is important as a contribution to better measurement of consumption poverty; but it is not appropriate to consider the dynamics of poverty, even on an intrayear basis.

\section{(d) One-off measures that capture dynamics}

As discussed above, illiteracy - or more debatably height for age malnutrition or illiteracy - can be considered as measures of longer term well-being. In addition, a low level of assets may be considered as a good indicator of chronic deprivation (although asset holding can fluctuate over relatively short time periods). This is an important and valuable approach, but to date there has been relatively little quantitative assessment of this potentially rich source of information.

This approach has been considered to some extent based on anthropometric measures such as height for age, which though static in measurement, can be considered dynamic by design. Moreover, they have the advantage of being individually collected and provide insights into the distribution of intrahousehold resources (unlike most of the measures discussed elsewhere in this paper). Though primarily used for children under the age of five years, they are still useful in picking up an element of an individual's history. Evidence from China by Morgan (2000) based on anthropometric data shows that the average height of school children has increased with family incomes and the decline of poverty-in other words, that there is declining chronic deprivation according to this key measure of nutritional status.

Unfortunately, it is less feasible to use other anthropometric measures, such as weight for height or the body mass index (BMI) ${ }^{15}$ as a measure of chronic deprivation in the absence of panel data, as such measures are less informative about past malnutrition.

In summary, it is important to recognize that longitudinal or panel data will often not be available, and even where they do have some associated problems, for instance, the effects of measurement error and possible systematic patterns of attrition. As argued in this section, it is possible to draw inferences or conclusions about poverty dynamics in general and chronic poverty specifically even in the absence of panel data. Some assumptions, or sometimes limitations, are implicit in applying some of these methods but they do offer other important advantages. In instances where panel data are available it is important to consider the extent to these alternative methods give similar conclusions to the analysis based on the panel data, in other words, to assess whether the assumptions seem reasonable.

\section{CONCLUSIONS}

Even though much poverty clearly is transient, this paper has argued that chronic poverty is an important phenomenon quantitatively in most low-income countries, potentially more so than has been assumed based on in several recent studies. This is especially so taking account of the fact that the inevitable consequence of measurement error (certainly an important issue in using panel data) will be to show more variability in income or consumption than there really is.

In addition, chronic poverty is clearly a distinct phenomenon. It is strongly associated with disadvantages that are difficult to reverse quickly such as a lack of assets (physical and human, as suggested among others by Deininger \& Okidi, 2002), being trapped in low-productivity activities (itself perhaps a consequence of poverty), disadvantageous demographic characteristics (notably a high dependency ratio), 
and location in remote or otherwise disadvantaged areas. Transient poverty by contrast is more typically associated with cases where households have very little ability to insure themselves against fluctuations due to either external factors such as prices, climate or job availability, or household level shocks such as serious illness or death. Of course, it may also be associated with relatively low levels of asset holdings. Moreover, these broad generalizations appear to hold even against the backdrop of a range of different approaches to defining chronic and transient poverty. This has clear policy implications.

These conclusions are largely based on chronic monetary poverty as identified based on panel data. Important as this is, there is also a need to broaden the perspective on chronic poverty, and to consider many other aspects of chronic deprivation that need to be examined in much more detail. One that relates to the monetary dimension, among others, is to consider further the reliability and usefulness of results of applying techniques to identifying what is considered to be chronic and transient poverty without using panel data. If reliable then they will enable the chronic/transient distinction to be made on a more quickly and easily, and incorporated into policy discussions. But a much more important priority is to be able to distinguish chronic and transient deprivation in other dimensions where this distinction is meaningful, and to consider the relationships between these different dimensions.

\section{NOTES}

1. While cohort analysis (analysis of groups) based on repeated cross-sections is also valuable, it can only provide information on the cohorts identified as a whole, and not on individual households or people within the cohort.

2. This is less an issue for some panel surveys in industrialized countries which follow individuals rather than households.

3. Difficulties arising from using arbitrary cut-off points can be overcome by using tests of stochastic dominance (Atkinson, 1987).

4. This might suggest that shorter panel datasets are less reliable.

5. They exploited the fact that consumption and income tend to be well correlated and therefore can be used as instruments for each other in econometric models (McCulloch \& Baulch, 2000, p. 23).

6. The adjusted income variable shared the same estimated mean as the true income variable but has the estimated variance of the true income variable, rather than that of the observed income (McCulloch \& Baulch, 2000, p. 23).

7. This was based on a regression of consumption on prices, wages, shocks (seasonal effect variables), and on a number of controls for changes in household size and composition, which the authors used $t$ test for the extent of consumption smoothing.

8. At the same time though a longer time horizon may also mean longer gaps over which individuals are not observed.
9. More surprisingly, $27.6 \%$ of those identified as being persistently poor are considered to be innately nonpoor-i.e., given their characteristics and the coefficients of the fixed effects regression equation for income. Given the demanding criteria for being persistently poor, this does raise the issue of how accurately the permanent and transitory components have been distinguished.

10. See Yaqub (2000), for a discussion of chronic relative poverty and a tabulation of the available data.

11. This illustrates the importance of using productive policies as a means for poverty reduction in a subsistence economy (Deininger \& Okidi, 2002, p. 19).

12. This is confirmed to a large extent by the large household mobility across quintiles in all seasons (Muller, 2000, p. 36).

13. There is also quite a lot of evidence on factors influencing poverty transitions in the 1970s and 1980s in the United States (Bane \& Ellwood, 1986; Stevens, 1994).

14. High vulnerability is defined as a greater than a $50 \%$ probability of falling into poverty, based upon household characteristics and current consumption.

15. The BMI is defined as an individual's weight in kilograms divided by the square of the individual's height in metres. Baulch and Masset (2003) examines BMI as an indicator of chronic poverty in Vietnam. 


\section{REFERENCES}

Adam, R. H., \& Jane, J. H. (1995). Sources of income inequality and poverty in rural Pakistan. International Food Policy Research Institute Research Report 102. Washington DC: IFPRI.

Aliber, M. (2001). An overview of the incidence and nature of chronic poverty in South Africa. CPRC working paper no. 3. IDPM, Manchester: University of Manchester.

Appleton, S. (2001). Education, incomes and poverty in Uganda in the 1990s. CREDIT research paper no. 01/ 22. Nottingham: University of Nottingham.

Atkinson, A. B. (1987). On the measurement of poverty. Econometrica, 55(4), 749-764

Bane, M., \& Ellwood, D. (1986). Slipping into and out of poverty: the dynamics of spells. Journal of Human Resources, 21(1), 1-23.

Baulch, B., \& Hoddinott, J. (2000). Economic mobility and poverty dynamics in developing countries. Journal of Development Studies, 36(6), 1-24.

Baulch, B., \& Masset, E. (2003). Do monetary and nonmonetary indicators tell the same story about chronic poverty? A study of Vietnam in the 1990s. World Development, 31(3), 441-453.

Baulch, B., \& McCulloch, N. (1998). Being poor and becoming poor: poverty status and poverty transitions in rural Pakistan. IDS working paper no. 79. Brighton: Institute of Development Studies.

Campa, M., \& Webb, R. (1999). Mobility and poverty dynamics in the 1990s. Paper presented at IDS/ IFPRI workshop on poverty dynamics, April 1999, Institute of Development Studies, University of Sussex.

Carter, M. R., \& May, J. (1999). One kind of freedom: poverty dynamics in post apartheid South Africa. Staff paper no. 427, University of Wisconsin-Madison, December.

Canagarajah, S., \& Thomas, S. (2001). Poverty in a wealthy economy: the case of Nigeria. Journal of African Economies, 10(2), 143-173.

Coulombe, H., \& McKay, A. (2002). The evolution of poverty and inequality in Ghana over the 1990s: a study based on the Ghana living standards surveys. Mimeo: University of Nottingham, September.

Deininger, K., \& Okidi, J. (2002). Growth and poverty reduction in Uganda, 1992-2000: panel data evidence. Kampala, Uganda: Economic Policy Research Council.

Dercon, S., \& Krishnan, P. (2000). Vulnerability, seasonality and poverty in Ethiopia. Journal of Development Studies, 36(6), 82-100.

Gaiha, R. (1988). Income mobility in rural India. Economic Development and Cultural Change, 36(2), 279-302.

Gaiha, R. (1992). On the chronically poor in rural India. Journal of International Development, 4(3), 273 289.

Gaiha, R., \& Deolaiker, A. B. (1993). Persistent, expected and innate poverty: estimates for semi arid rural South India. Cambridge Journal of Economics, 17(4), 409-421.
Gibson, J. (2001). Measuring chronic poverty without a panel. Journal of Development Economics, 65, 243266.

Glewwe, P., \& Hall, G. (1998). Are some groups more vulnerable to macroeconomic shocks than others? Hypothesis tests based on panel data from Peru. Journal of Development Economics, 56(1), 181-206.

Glewwe, P., \& Jacoby, H. (2000). Recommendations for collecting panel data. In M. Grosh, \& P. Glewwe (Eds.), Designing household survey questionnaires for developing countries: lessons from 15 years of the Living Standards Measurement Study. New York: Oxford University Press for the World Bank.

Grootaert, C., \& Kanbur, R. (1995). The lucky few amidst economic decline: distributional change in Côte d'Ivoire as seen through panel datasets, 198588. Journal of Development Studies, 31(4), 603-619.

Grootaert, C., Kanbur, R., \& Oh, G.-T. (1997). The dynamics of welfare gains and losses: an Africa case study. Journal of Development Studies, 33(5), 635657.

Gunning, J. W., Hoddinott, J., Kinsey, B., \& Owens, T. (2000). Revisiting forever gained: income dynamics in the resettlement areas of Zimbabwe, 1983-1996. Journal of Development Studies, 36(6), 131-155.

Hulme, D., \& Shepherd, A. (2003). Conceptualizing chronic poverty. World Development, 31(3), 403423.

Hulme, D., Moore, K., \& Shepherd, A. (2001). Chronic poverty: meanings and analytical frameworks. CPRC working paper 2. Manchester: IDPM, University of Manchester.

Jalan, J., \& Ravallion, M. (1998). Transient poverty in post-reform rural China. Journal of Comparative Economics, 26(2), 338-357.

Jalan, J., \& Ravallion, M. (1999). Do transient and chronic poverty in rural China share common causes? Paper presented as IDS/IFPRI workshop on poverty dynamics. IDS, April.

Jalan, J., \& Ravallion, M. (2000). Is transient poverty different? Evidence for rural China. Journal of Development Studies, 36(6), 82-99.

Lanjouw, P., \& Stern, N. (1991). Poverty in Palanpur. World Bank Economic Review, 5(1), 23-55.

Lanjouw, P., \& Stern, N. (1993). Agricultural change and inequality in Palanpur, 1957-84. In K. Hoff, A. Braverman, \& J. Stiglitz (Eds.), The economics of rural organization. Oxford: Oxford University Press.

Lipton, M. (1988). The poor and the poorest: some interim findings. World Bank discussion papers no. 25. Washington, DC: The World Bank.

McCulloch, N., \& Baulch, B. (1999). Distinguishing the chronically from the transitory poor-evidence from Pakistan. IDS working paper no. 97. Brighton: Institute of Development Studies, University of Sussex.

McCulloch, N., \& Baulch, B. (2000). Simulating the impact of policy on chronic and transitory poverty in Rural Pakistan. Journal of Development Studies, 36(6), 100-130. 
McKay, A., \& Lawson, D. (2002). Chronic poverty: a review of current quantitative evidence. CPRC working paper no. 15. Manchester: IDPM, University of Manchester.

Mehta, A. K., \& Shah, A. (2001). Chronic poverty in India: overview study. CPRC working paper no. 7 . Manchester: IDPM, University of Manchester.

Morgan, S. L. (2000). Richer and taller: stature and living standards in China, 1979-1995. China Journal, 44(July), 1-39.

Muller, C. (2000). Transient-seasonal and chronic poverty of peasants: evidence from Rwanda. Discussion papers in economics no. 00/9. University of Nottingham, April.

Okidi, J., \& Kempaka, G. (2002). An overview of chronic poverty and development policy in Uganda. CPRC working paper no. 11. Manchester: IDPM, University of Manchester.

Republic of Rwanda (2002). A profile of poverty in Rwanda. Ministry of Finance and Economic Plan- ning, National Poverty Reduction Programme and Statistics Department, February.

Scott, C. (1992). Estimation of annual expenditure from one month cross sectional data in a household Survey. Inter-Stat, 8(March), 57-65.

Scott, C. D. (2001). Mixed fortunes: a study of poverty mobility among small farm households in Chile, 1968-86. Journal of Development Studies, 36(6), 155181.

Stevens, A. H. (1994). The dynamics of poverty spells: updating Bane and Ellwood. American economic review-papers and proceedings. pp. 34 37.

Suryahadi, A., \& Sumarto, S. (2001). The chronic poor, the transient poor, and the vulnerable in Indonesia before and after the crisis. SMERU Research Institute Working Paper, May.

Yaqub, S. (2000). Poverty dynamics in developing countries. IDS Development Bibliography, University of Sussex, April. 